\title{
Pollution due to Textile Industries along Dombivali Industrial Belt of Mumbai, India
}

\author{
P. U. Singare ${ }^{1, \star}$, S. S. Dhabarde ${ }^{2,3}$ \\ ${ }^{1}$ Department of Chemistry, Bhavan's College, Munshi Nagar, Andheri (West), Mumbai, \\ Maharashtra 400058, India \\ ${ }^{2}$ Department of Chemistry, K.V. Pendharkar College, Dombivali (East), Dist. Thane, \\ Maharashtra 421201, India \\ ${ }^{3}$ Department of Chemistry, Pacific University of Higher Education \& Research University, \\ Udaipur, Rajasthan, India \\ *E-mail address: pravinsingare@gmail.com
}

\begin{abstract}
The paper deals with monitoring of pollution arising due to textile based industries located along the Dombivali industrial belt of Mumbai, India. The study was carried for the period of one year from June, 2012 to May, 2013 to study the level of toxic heavy metals and the physico-chemical properties of waste water effluents discharged from the above industries. The concentration level of majority of toxic heavy metals like $\mathrm{Cu}, \mathrm{Ni}, \mathrm{Pb}$, and $\mathrm{Zn}$ were reported to be maximum of 45.58, 2.00, 2.06 and $9.20 \mathrm{ppm}$ respectively in the month of April, while $\mathrm{Cr}$ and $\mathrm{Fe}$ concentration levels were found to be 2.50 and $55.30 \mathrm{ppm}$ in the month of March. The effluent samples collected in the month of July was reported to show high BOD content of $564 \mathrm{ppm}$, while COD content was maximum of $2436 \mathrm{ppm}$ in the month of October. The effluent samples collected in the month of January was having very low DO content of $3.21 \mathrm{ppm}$ and high cyanide content of $0.09 \mathrm{ppm}$. The alkalinity, hardness and chloride content were maximum of 2158, 198 and $2765 \mathrm{ppm}$ respectively in the effluent samples collected in the month of February. The effluents were having high total solid content of 8269 ppm during the month of April, while the salinity and phosphate contents were reported high of 5.64 and $125.70 \mathrm{ppm}$ during the month of May. It was observed that the concentration level of majority of toxic heavy metals and the values of various physico-chemical parameters were above the tolerable limit set for inland surface water. The present experimental data on environmental risk assessment studies due to textile industries may be regarded as an aid towards a better understanding of the problem arising due to such industries. There is a need to convey the message that prevention of adverse health effects and promotion of health are profitable investments for employers and employees as a support to a sustainable development of economics.
\end{abstract}

Keywords: industrial effluents; industrial pollution; physico-chemical properties; toxic heavy metals; textile industries; Dombivali industrial belt; Mumbai 


\section{INTRODUCTION}

The textile industry is one of the oldest and largest organised sectors in India. With the increased demand for textile products, the textile industry and its wastewaters have increased proportionally. There are over 7000 large-scale textile industries in India concentrated mainly in Gujarat, Maharashtra, Rajasthan and Tamil Nadu states. The textile printing and dyeing industry is a water-intensive industry requiring a large volume of freshwater at various steps of printing and therefore, the volume of wastewater produced is equally large. These industries can generate both inorganic and organic waste mixed with waste waters from the production processes, which when discharged into the receiving water bodies can leads to change in both biological and chemical parameters of water [1].

These disposal practices have contaminated the environment and caused adverse effects on the crops, flora, and fauna in many places of India [2, 3]. Such discharge of textile wastewaters is of great concern since the discharges are mostly made untreated or partially treated due to poor enforcement of existing laws in the developing world including India [4]. As a result these industries are the main sources of severe pollution problems worldwide [5]. The key environmental issues associated with textile industry are water use, treatment and disposal of aqueous effluent [6]. Effluents from textile industries are complex mixtures of chemicals varying in quantity and quality. These effluents, with their high $B O D$ (Biological Oxygen Demand), COD (Chemical Oxygen Demand) and suspended solids, are very toxic in nature as they contain large quantities of dyes (azoic, indigo and aniline), bleaching agents, salts, acids/alkalies and heavy metals in high concentration [4].

Textile wastewaters display a great chemical Introductoin complexity and variability in terms of quantities and pollution load, type of dyes, $\mathrm{pH}$, and temperature [7]. Waste water generated by different production steps of a textile mill have high $\mathrm{pH}$, temperature, detergents, oil, suspended and dissolved solids, dispersants, levelling agents, toxic and nonbiodegradable matter, colour and alkalinity. Effluents from these industries also contain undesirable quantities of pollutants showing a vast difference in composition, molecular weight, toxicity etc. and need to be treated [8]. Important pollutants in textile effluent are mainly recalcitrant organics, colour, toxicants and surfactants, chlorinated compounds $(A O X)$. The textile wastewaters are characterized by extreme fluctuations in many parameters such as chemical oxygen demand $(C O D)$, biochemical oxygen demand $(B O D), \mathrm{pH}$, colour and salinity [9].

Considering the severe environmental impact of various toxic pollutants released from textile based industries across the globe in general and India in particular, in the present investigation attempts was made to carry out the comprehensive survey of pollution arising due to such industries located in Dombivali MIDC industrial belt which is considered to be one of the most polluted industrial belts of Mumbai.

\section{EXPERIMENTAL}

\section{1. Study area}

The Dombivali industrial area was established by Maharashtra Industrial Development Corporation (M.I.D.C) in 1964. The industrial belt occupies an area of about 347.88 hector, is located in south of Ulhas River and about $45.00 \mathrm{~km}$ from Mumbai international airport. There are about 30 highly polluting small/ medium/ large scale chemical industries located in this industrial belt. 
Quantity of industrial effluent generated in the industrial area is about 14 MLD, which is finally discharged into the creek through open drainages which was passing through residential area $[10]$.

\section{2. Climatic condition}

Dombivali enjoys a tropical climate with mean annual temperature of $24.3^{\circ} \mathrm{C}$ (min) to $32.9^{\circ} \mathrm{C}(\max )$. The hottest and driest part of the year is April-May, when temperature rises to $38.0{ }^{\circ} \mathrm{C}$.

The humidity is usually in the range of 58 to $84 \%$ and sea breeze in the evening hours is a blessing to combat the high temperature and humidity during summer months. The average southwest monsoon rainfall is in the range of $1850 \mathrm{~mm}$ to $2000 \mathrm{~mm}$. The average annual rainfall in the region is the range from 1286 to $1233 \mathrm{~mm}$ [10].

\section{3. Requirements}

All the chemicals and reagent used for analysis were of analytical reagent grade. The glasswares used in the analysis were washed with distilled de-ionized water; the pipettes and burette were rinsed with the experimental solution before final use.

\section{4. Industrial Effluent Sampling and Preservation}

The industrial waste water effluent samples were collected randomly twice in a month in morning, afternoon and evening session from three representative textile manufacturing units of Dombivali industrial belt of Mumbai.

The samples were collected every month from June, 2012 to May, 2013. Polythene bottles of $2.5 \mathrm{~L}$ and $2.0 \mathrm{~L}$ were used to collect the grab water samples (number of samples collected, $n=20$ ).

The bottles were thoroughly cleaned with hydrochloric acid, washed with tape water to render free of acid, washed with distilled water twice, again rinsed with the water sample to be collected and then filled up the bottle with the sample leaving only a small air gap at the top. The sample bottles were stoppard and sealed with paraffin wax.

\section{5. Physico-chemical Study}

The samples were collected were analyzed for $\mathrm{pH}$, conductivity, alkalinity, hardness, salinity, chloride, cyanide, phosphate content, Total Dissolved Solids (T.D.S), Total Suspended Solids (T.S.S), Total Solids (T.S), Dissolved Oxygen (D.O), Bio-chemical Oxygen Demand (B.O.D) and Chemical Oxygen Demand (C.O.D) values. The techniques and methods followed for collection, preservation, analysis and interpretation are those given by Rainwater and Thatcher [11], Brown et al. [12], I.C.M.R [13], Hem [14] and A.P.H.A [15].

\section{6. Heavy Metal Analysis by AAS Technique}

Water samples $(500 \mathrm{~mL})$ were filtered using Whatman No. $41(0.45 \mu \mathrm{m}$ pore size $)$ filter paper for estimation of dissolved metal content. Filtrate $(500 \mathrm{~mL})$ was preserved with $2 \mathrm{~mL}$ nitric acid to prevent the precipitation of metals. The samples were concentrated on a water bath depending on the suspected level of the metals [16]. The analysis for the majority of the trace metals like copper $(\mathrm{Cu})$, nickel $(\mathrm{Ni})$, chromium $(\mathrm{Cr})$, lead $(\mathrm{Pb})$, iron $(\mathrm{Fe})$ and zinc $(\mathrm{Zn})$ was done by Perkin Elmer ASS-280 Flame Atomic Absorption Spectrophotometer. The calibration curves were prepared separately for all the metals by running different 
concentrations of standard solutions. A reagent blank sample was run throughout the method, and the blank readings were subtracted from the samples to correct for reagent impurities and other sources of errors from the environment. Average values of three replicates were taken for each determination.

\section{RESULTS AND DISCUSSION}

The experimentally measured pollution data on heavy metal content and physicochemical properties of industrial waste water effluents released from textile based industries located along Dombivali industrial belt of Mumbai is presented in Tables 1 and 2.

Table 1. Physico-chemical properties of the effluents released from Textile industries located along Dombivali Industrial Belt of Mumbai, India.

\begin{tabular}{|c|c|c|c|c|c|c|c|c|c|c|c|c|}
\hline 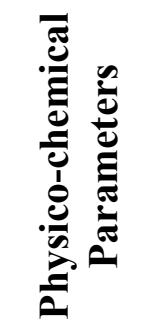 & 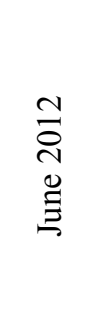 & $\begin{array}{l}\underset{D}{D} \\
\text { N } \\
\frac{\lambda}{\Xi}\end{array}$ & 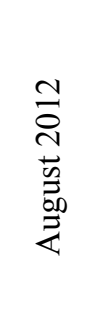 & 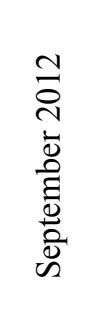 & 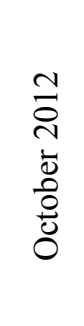 & 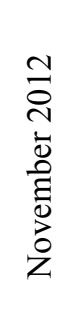 & 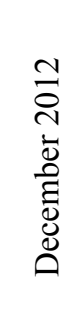 & 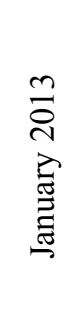 & 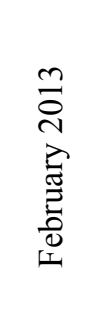 & 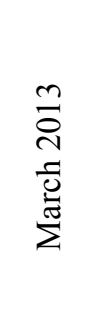 & 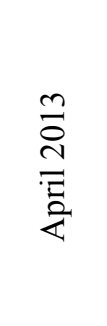 & 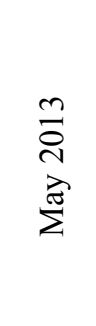 \\
\hline $\mathrm{pH}$ & 8.40 & 9.08 & 9.30 & 8.62 & 10.08 & 9.85 & 9.40 & 10.59 & 9.50 & 9.00 & 8.05 & 9.50 \\
\hline $\begin{array}{l}\text { Conductivity } \\
(\mu \mathrm{mhos} / \mathrm{cm})\end{array}$ & 29600 & 25885 & 26750 & 29800 & 7168 & 8046 & 7201 & 8118 & 8160 & 9675 & 8201 & 8165 \\
\hline $\begin{array}{l}\text { Alkalinity } \\
\text { (ppm) }\end{array}$ & 235 & 357 & 439 & 828 & 1408 & 1570 & 2058 & 1978 & 2158 & 1981 & 2055 & 2147 \\
\hline $\begin{array}{l}\text { Hardness } \\
\text { (ppm) }\end{array}$ & 173 & 157 & 126 & 120 & 98 & 151 & 177 & 189 & 198 & 189 & 197 & 177 \\
\hline $\begin{array}{c}\text { Salinity } \\
\text { (ppm) }\end{array}$ & 5.42 & 5.00 & 4.95 & 5.50 & 4.37 & 4.15 & 5.63 & 4.25 & 5.61 & 4.97 & 5.45 & 5.64 \\
\hline $\mathrm{Cl}^{-}(\mathrm{ppm})$ & 2230 & 2090 & 1348 & 1251 & 1010 & 1490 & 1780 & 2371 & 2765 & 2541 & 2387 & 2750 \\
\hline $\mathrm{CN}^{-}(\mathrm{ppm})$ & 0.01 & 0.05 & 0.04 & 0.03 & 0.07 & 0.08 & 0.06 & 0.09 & 0.08 & 0.07 & 0.06 & 0.03 \\
\hline $\begin{array}{l}\text { Phosphates } \\
\text { (ppm) }\end{array}$ & 5.78 & 9.36 & 8.43 & 9.79 & 10.38 & 15.78 & 20.64 & 80.76 & 105.53 & 109.40 & 110.60 & 125.70 \\
\hline TDS (ppm) & 6530 & 5607 & 6706 & 4905 & 4790 & 4876 & 5097 & 5982 & 6000 & 6251 & 6519 & 6399 \\
\hline TSS (ppm) & 222 & 450 & 784 & 810 & 980 & 996 & 1360 & 1549 & 1740 & 1890 & 1750 & 1718 \\
\hline TS (ppm) & 6752 & 6057 & 7490 & 5715 & 5770 & 5872 & 6457 & 7531 & 7740 & 8141 & 8269 & 8117 \\
\hline D.O (ppm) & 4.50 & 4.00 & 3.33 & 4.26 & 3.96 & 4.75 & 4.24 & 3.21 & 4.85 & 4.30 & 4.21 & 3.33 \\
\hline $\begin{array}{l}\text { B.O.D } \\
\text { (ppm) }\end{array}$ & 430 & 564 & 520 & 432 & 536 & 400 & 432 & 439 & 445 & 454 & 421 & 425 \\
\hline $\begin{array}{l}\text { C.O.D } \\
\text { (ppm) }\end{array}$ & 486 & 544 & 875 & 1440 & 2436 & 2265 & 2300 & 2320 & 2359 & 2433 & 2360 & 2346 \\
\hline
\end{tabular}


Table 2. Heavy Metal content in the effluents released from Textile industries located along Dombivali Industrial Belt of Mumbai, India.

\begin{tabular}{|c|c|c|c|c|c|c|c|c|c|c|c|c|}
\hline 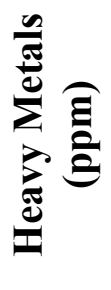 & 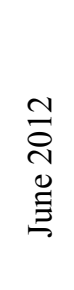 & $\begin{array}{l}\tilde{a} \\
\stackrel{\sim}{1} \\
\stackrel{2}{\Xi}\end{array}$ & 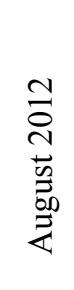 & 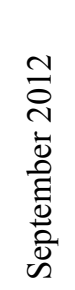 & 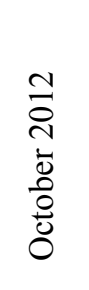 & 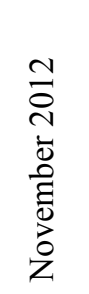 & 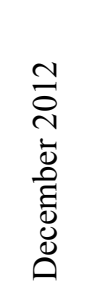 & 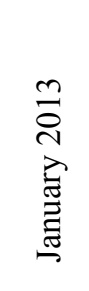 & 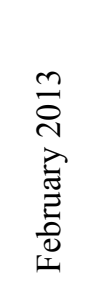 & 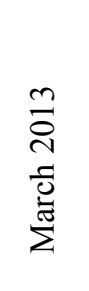 & 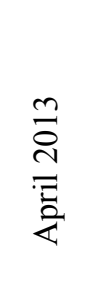 & 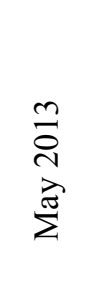 \\
\hline $\mathrm{Cu}$ & 0.52 & 0.87 & 3.59 & 7.39 & 9.89 & 12.78 & 20.56 & 35.4 & 42.11 & 43.9 & 45.58 & 42.94 \\
\hline $\mathrm{Ni}$ & 0.87 & 0.60 & 0.90 & 0.88 & 0.58 & 1.05 & 1.12 & 1.10 & 1.14 & 1.23 & 2.00 & 1.75 \\
\hline $\mathrm{Cr}$ & 0.59 & 0.68 & 0.59 & 0.55 & 0.69 & 1.50 & 1.49 & 1.70 & 1.80 & 2.50 & 1.72 & 2.05 \\
\hline $\mathrm{Pb}$ & 0.17 & 0.46 & 0.37 & 0.56 & 0.53 & 1.32 & 1.40 & 1.45 & 1.47 & 1.98 & 2.06 & 1.98 \\
\hline $\mathrm{Fe}$ & 2.06 & 1.24 & 5.64 & 6.87 & 12.38 & 20.56 & 34.66 & 40.12 & 54.38 & 55.30 & 50.23 & 52.29 \\
\hline $\mathrm{Zn}$ & 1.14 & 1.96 & 1.50 & 2.08 & 2.65 & 3.76 & 5.60 & 7.89 & 7.56 & 7.55 & 9.20 & 8.54 \\
\hline
\end{tabular}

Trace elements are those elements which are present in relatively low concentration of less than few ppm. Among the special group of trace elements are the heavy metals which are having the potential to create health hazards among humans, plants and other aquatic biological life. Under the group of heavy metals are $\mathrm{Cr}, \mathrm{Ni}, \mathrm{Zn}, \mathrm{Cu}, \mathrm{Pb}$ and $\mathrm{Fe}$. They are classified under the group of heavy metals because in metallic form they have the densities higher than $4 \mathrm{~g} / \mathrm{cm}^{3}$. The $C u$ content was found to vary in the range of $0.52 \mathrm{ppm}$ in the month of June to $45.58 \mathrm{ppm}$ in the month of April. The values reported were above the permissible limit of $0.05 \mathrm{ppm}$ set by W.H.O and $1.0 \mathrm{ppm}$ as per the USPH standards. The Ni content was found to be minimum of $0.58 \mathrm{ppm}$ in the month of October to maximum of $2.00 \mathrm{ppm}$ in the month of April.

The overall experimental observed $\mathrm{Ni}$ concentration was above the maximum limit of $0.1 \mathrm{ppm}$ set by W.H.O. The $\mathrm{Cr}$ content was found to vary in the range of $0.55 \mathrm{ppm}$ in the month of September to $2.50 \mathrm{ppm}$ in the month of March. The Cr values reported were above the maximum permissible limit of $0.05 \mathrm{ppm}$ set by $W . H . O$ [17]. The $P b$ content was found to vary in the range of $0.17 \mathrm{ppm}$ in the month of June to $2.06 \mathrm{ppm}$ in the month of April. The values of $P b$ were extremely above the general standard limit of $0.1 \mathrm{ppm}$ lead set for effluents discharge in inland surface water [18]. The $F e$ content was found to vary in the range of 1.24 $\mathrm{ppm}$ in the month of July to $55.30 \mathrm{ppm}$ in the month of March. The reported level of $F e$ from the month of August to May were very much above the permissible limit of $3.0 \mathrm{ppm}$ iron set for effluents discharge in inland surface water [18]. The $Z n$ content was found to vary in the range of $1.14 \mathrm{ppm}$ in the month of June to $9.20 \mathrm{ppm}$ in the month of April. The reported level of $Z n$ in the effluent samples collected from the month of December to May were above the general standard limit of $5.0 \mathrm{ppm} Z n$ set for effluents discharge in inland surface water [18]. 
In any environmental monitoring study related to pollution of surface water, physicochemical parameters gives valuable information regarding the pollution load. It is found that most of the industries in India are located near the water bodies because of their extensive requirement of water for various industrial activities. The industrial waste water is generally discharged in drainages which finally enter the nearby water bodies creating extensive pollution creating threat to the aquatic life and health of surrounding human population. The most common physico-chemical parameters are $\mathrm{pH}$, conductivity, hardness, alkalinity, suspended and dissolved solids, BOD, COD and DO.

These parameters generally decide the extent of pollution and help in planning the waste water treatment technology which is to be adopted. In the present investigation it was observed that the $\mathrm{pH}$ of collected effluents was found to vary in the range of 8.05 in the month of April to maximum of 10.59 in the month of January. During major assessment period, the $\mathrm{pH}$ values recorded were above the permissible $\mathrm{pH}$ range of 5.5 to 9.0 as set for inland surface water subjected to pollution load [18-28]. The conductivity values recorded was found to vary from minimum of $7168 \mu \mathrm{mhos} / \mathrm{cm}$ in the month of October to maximum of $29800 \mu \mathrm{mhos} / \mathrm{cm}$ in the month of September. The effluent samples collected in the month of July was reported to show high BOD content of $564 \mathrm{ppm}$, while COD content was maximum of $2436 \mathrm{ppm}$ in the month of October. The effluent samples collected in the month of January was having very low DO content of $3.21 \mathrm{ppm}$ and high cyanide content of 0.09 ppm. The alkalinity, hardness and chloride content were maximum of 2158, 198 and 2765 ppm respectively in the effluent samples collected in the month of February. The effluents were having high total solid content of $8269 \mathrm{ppm}$ during the month of April, while the salinity and phosphate contents were reported high of 5.64 and $125.70 \mathrm{ppm}$ during the month of May.

\section{CONCLUSION}

Currently, India is considered to be one of attractive destinations for investment in the world economy. Apart from its large domestic consumer base of one billion, it also offers a perfect setting for basing manufacturing and other services to serve the global market owing to its cheap labour. With the Indian Government making an all out effort to increase Foreign direct investment to USD 50 billion within 5 years, huge investments can also be expected in manufacturing chemicals, pesticides, textiles and every imaginable product; increase in waste output and spread of toxic hotspots across the country. Polluting Industrial discharges wastewater is one of the main causes of irreversible ecosystem degradation.

The growing ecosystem degradation due to rapid industrialization in India is particularly more damaging to the vast population of poor in the country who depend solely on ecosystem services, and are sometimes the principal factor causing poverty and social conflict. The time has come to move towards ecosystem specific discharge standards to maintain the health and productivity of natural resources on which the majority of Indians are dependent.

Here the right way forward will be to empower the local communities to ensure their right to a healthy environment and ultimately their survival. With the country already losing around $10 \%$ of its GDP due to environmental damage; the future portends swift economic growth in the short term with irreversible long term consequences to ecosystems if environmental regulation is not tightened. 


\section{References}

[1] Gomez N., Sierra M. V., Cortelezzi A., Rodrigues Capitulo A., Ecotoxicol. Environ. Saf. 69 (2008) 472-479.

[2] Sharma K. P., Chaturvedi R. K., Sharma K., Bharawaj S. M., Jaipur. Tropical Ecology 42(1) 92001) 69-82.

[3] Sharma K. P., Sharma K., Bhardwaj S. M., Chaturvedy R. K., Sharma S., Journal of Indian Botanical Society 78(I\&II) (1999) 71-85.

[4] Subhasini Sharma, Kalpana Arti Shweta, V. Suryavathi, Pawan K. Singh, Ramesh, Shipra, K. P. Sharma, Australasian Journal Of Ecotoxicology 13 (2007) 81-85.

[5] Enayatzamir K, Alikhani H. A., et al. (2010). Environ Sci. Pollut Res Int. 17(1) (2010) 145-53.

[6] Odjegba V. J., Bamgbose N. M., African Journal of Environmental Science and Technology 6(11) (2012) 438-445.

[7] Hai F. I., Yamamoto K., Fukushi K., Crit. Rev. Environ. Sci. Technol. 37 (2007) 315-377.

[8] Aksu Z., Process Biochem. 40 (2005) 997-1026.

[9] Talarposhti A. M., Donelly T., Anderson G. K., Water Research 35(2) (2001) 425.

[10] Action Plan for Industrial Cluster "Dombivali", Maharashtra Pollution Control Board, November 2010. http://www.mpcb.gov.in

[11] Rainwater F. H., Thatcher L. L., U.S. Geol. Surv. Water Supply Papers 1454 (1960) 1-301.

[12] E. Brown, M. W. Skougstad, M. J. Fishman, 'Methods for collection and analysis of Water samples for dissolved minerals and gases', Techniques of Water Resources Investigations of the U.S. Geological Survey, Vol. 160, Book 5, Chapter A1 (1970).

[13] Indian Council of Medical Research (ICMR) Manual of Standards of Quality for Drinking Water Supplies, (1975).

[14] J. D. Hem, 'Study and Interpretation of Chemical Characteristics of Natural Water', $3^{\text {rd }}$ ed., U.S. Geological Survey, Washington (1985).

[15] American Public Health Association (APHA). Standard Methods for Estimation of Water and Wastewater, 19th ed., American Water Works Association, Water Environment Federation, Washington, (1995).

[16] Chen M., Ma L. Q., Soil Science Society of American Journal 65(2) (2010) 491-499.

[17] A. K. De, Environmental Chemistry, pp. 232-272, 4th ed., New Age International (P) Ltd., New Delhi, India (2002).

[18] The Environment (Protection) Rules (1986) Available at: http://www.cpcb.nic.in/GeneralStandards.pdf (assessed on November 2011).

[19] P. Daniszewski, International Letters of Chemistry, Physics and Astronomy 4 (2012) 112-118. 
[20] E. Cyrania, P. Daniszewski, B. Draszawka-Bołzan, International Letters of Chemistry, Physics and Astronomy 5 (2012) 96-103.

[21] E. Cyraniak, P. Daniszewski, B. Draszawka-Bołzan, International Letters of Chemistry, Physics and Astronomy 5 (2012) 88-95.

[22] P. Daniszewski, R. Konieczny, International Letters of Chemistry, Physics and Astronomy 4 (2013) 91-97.

[23] P. Daniszewski, R. Konieczny, International Letters of Chemistry, Physics and Astronomy 4 (2013) 98-104.

[24] P. U. Singare, M. S. Talpade, D. V. Dagli, V. G. Bhawe, International Letters of Chemistry, Physics and Astronomy 8(2) (2013) 94-104

[25] P. U. Singare, M. S. Talpade, D. V. Dagli, V. G. Bhawe, International Letters of Chemistry, Physics and Astronomy 8(2) (2013) 105-112

[26] P. Daniszewski, International Letters of Chemistry, Physics and Astronomy 8(3) (2013) 269-278.

[27] P. Daniszewski, International Letters of Chemistry, Physics and Astronomy 8(3) (2013) 279-287.

[28] P. Daniszewski, International Letters of Chemistry, Physics and Astronomy 10(2) (2013) 218-226. 